\title{
ANÁLISE DE PESQUISAS EM EDUCAÇÃO EM CIÊNCIAS E ENSINO DE BIOLOGIA SOBRE EDUCAÇÃO DE JOVENS E ADULTOS (EJA) EM PERIÓDICOS BRASILEIROS
}

\author{
ANALYSIS OF RESEARCH IN SCIENCE EDUCATION AND \\ BIOLOGY TEACHING ON YOUTH AND ADULT EDUCATION (EJA) \\ IN BRAZILIAN JOURNAL
}

\begin{abstract}
Marsílvio Gonçalves Pereira (marsilvioeduc@ gmail.com)
Universidade Federal da Paraíba (UFPB) - GEPEBio (Grupo de Estudos e Pesquisas em Ensino de Biologia, Educação Científica e Ambiental) - Departamento de Metodologia da Educação/Centro de Educação/Universidade Federal da Paraíba
\end{abstract}

Julio César Rufino Ramos de Oliveira e-mail (juliocrro@hotmail.com)

Universidade Federal da Paraíba (UFPB) - GEPEBio (Grupo de Estudos e Pesquisas em Ensino de Biologia, Educação Científica e Ambiental)

Thiago dos Santos Ferreira e-mail (bimsantos301091@gmail.com)

Universidade Federal da Paraíba (UFPB) - GEPEBio (Grupo de Estudos e Pesquisas em Ensino de Biologia, Educação Científica e Ambiental)

Resumo: O artigo investiga publicações sobre Educação de Jovens e Adultos (EJA) em pesquisas em Educação em Ciências e Ensino de Biologia em periódicos nacionais. Foram identificados 20 trabalhos em cinco periódicos brasileiros do extrato Qualis A da CAPES (Ciência \& Educação; Investigações em Ensino de Ciências; Ensaio: Pesquisas em Educação em Ciências; Revista Brasileira de Pesquisa em Educação em Ciências e Alexandria). Entre estes, foram analisados 14 artigos através do título, resumo, palavraschave e leitura integral dos mesmos. As produções foram caracterizadas e classificadas segundo alguns descritores: distribuição geográfica (região de origem das pesquisas), foco temático e procedimentos metodológicos de investigação. Os resultados mostram que as pesquisas estão mais voltadas para estudos sobre 'estratégias para o ensinoaprendizagem de Ciências na EJA', 'concepções dos alunos acerca de temas relacionados à Ciência e à EJA' e 'currículo'. Aparecem ainda em pequena quantidade, pesquisas que focalizam em 'concepções de professores acerca do ensino de ciências na EJA'; 'análise de aspectos culturais do ensino na modalidade EJA' e 'formação de professores'.

Palavras-chave: Revisão Sistemática; Estado da Arte; Analise de Conteúdo.

Abstract: The article investigates publications about Youth and Adult Education (EJA) in research in Science Education and Biology Teaching in national journals. Twenty papers were identified in five brazilian journals of the Qualis A extract from CAPES (Science \& Education; Investigations in Science Teaching; Essay: Research in Science 
Education; Brazilian Journal of Science Education Research and Alexandria). Among these, 14 articles were analyzed through the title, abstract, keywords and integral reading of them. The productions were characterized and classified according to some descriptors: geographic distribution (region of origin of research), thematic focus and methodological procedures of investigation. The results show that researches are more focused on studies about 'strategies for teaching-learning Science in EJA', 'students conceptions about science-related themes and EJA' and 'curriculum'. There is still a small amount of research that focuses on 'teachers conceptions about teaching science in EJA'; 'Analysis of cultural aspects of teaching in the EJA modality' and 'teacher training'.

Keywords: Systematic Review; State of the Art; Content Analysis.

\section{INTRODUÇÃ̃}

A educação é de extrema importância para a formação do sujeito enquanto sujeito social, devendo ser acessada como um bem a toda população para a devida participação social de todos (CAVALCANTE, 2011; GEGLIO; SANTOS, 2011; RIBEIRO, 2002). Muitos sujeitos que, por diversos motivos, entre os quais, aspectos econômicos e sociais, tornam-se marginalizados pelo sistema educacional regular, tem na modalidade de Educação de Jovens e Adultos (EJA) uma oportunidade de ingressar ou retornar aos estudos (LOPES; SOUZA, 2005; SANTOS; SOUZA, 2011). É preciso perceber que essas pessoas não são crianças e, às vezes, não são jovens, são estudantes que tem contextos de vida bem diferenciados daqueles que estão na faixa etária condizente com a série em que se encontram (LOPES; SOUZA, 2005; CAVALCANTE, 2011).

As primeiras ações educacionais envolvendo jovens e adultos tinham como objetivos o ensino da leitura e escrita, com o passar do tempo o ensino se tornou mais amplo, focado nas demandas da sociedade (GOUVEIA; SILVA, 2015). A garantia de acesso a essa modalidade se respalda na LDBEN (BRASIL, 1996) e na Constituição Federal de 88 (BRASIL, 1988).

\footnotetext{
Mesmo, assim não se implantou nacionalmente uma política para EJA, nem se concretizou, como decorrência da conquista desse direito, um sistema nacional articulado de atendimento que permita que todos os cidadãos e cidadãs acima de 14 anos possam, pela escolarização, enfrentar os desafios de uma sociedade como a brasileira (HADDAD, 2007, p. 197).
}

Propor leis, pensar sobre formas de se implementar e gerenciar estas para que mais alunos sejam acolhidos e ter a oportunidade de voltar a estudar é de extrema importância 
em todo esse processo. Porém, ainda há muito para se melhorar no que diz respeito a essa modalidade de ensino, tanto em relação às práticas de ensino e aprendizagem quanto aos investimentos.

Se as limitações de investimentos já acontecem de forma assustadora no ensino regular, na EJA elas são ainda mais visíveis, uma vez que esta modalidade atende a um público que traz consigo a marca de ser excluído da escola e com baixa capacidade de mobilização e visibilidade social (GLEGIO; SANTOS, 2011, p. 77).

Segundo Cassab (2016) os estudantes de EJA evidenciam trajetórias de vulnerabilidades sociais diversas como pobreza, miséria, desemprego ou empregados informais nos limites da sobrevivência e trazem para o espaço-tempo escolar experiências consideradas não bem-sucedidas no "ensino regular", isto é, evasão, reprovação, problemas de frequência e que demandam metodologias de ensino diferenciadas (OLIVEIRA, 1999). Porém, na sociedade moderna, moldada pelos avanços tecnocientíficos, cada vez mais o mercado faz exigências na hora de contratar, pedindo conhecimentos e habilidades específicos e que só podem ser conseguidos por meio da escolarização, fazendo com que esses jovens e adultos busquem na EJA uma oportunidade para se atualizar para o mercado de trabalho (LOPES; SOUZA, 2005). Contudo, as propostas curriculares para EJA são bastante compactas, podendo vir a dificultar a aprendizagem dos alunos devido à sobrecarga de conteúdo em um curto espaço de tempo, principalmente em disciplinas como ciências e biologia, que abrangem muitas inter-relações com outras áreas do conhecimento, além de muitos termos e descrições científicas (MORAIS, 2009). Isso representa novos desafios aos educadores, que necessitam alinhar-se com universos etários, culturais e de expectativas muito distintos em relação à vida na escola e a cultura científica.

No que diz respeito à Educação em Ciências e Biologia, os documentos oficiais têm ressaltado a importância de que a educação científica pode contribuir para que os jovens e adultos compreendam a relevância social do conhecimento científico e a importância da articulação desse saber com os demais, a fim de que possam ter mais condições de enfrentar os desafios de uma sociedade em mudança contínua e tomar as decisões conforme seus anseios (BRASIL, 2002). Tal processo educacional, que pode promover a imersão dos sujeitos na cultura científica, pode proporcionar ao sujeito, enquanto cidadão, 
a capacidade de desenvolver reflexões críticas sobre suas necessidades e objetivos (SANTOS; SOUZA, 2011). Sendo assim, esse indivíduo torna-se capaz de se posicionar em meio a questões referentes à Ciência, Tecnologia, Sociedade e Ambiente, ou seja, através do processo de alfabetização científica (SASSERON, 2008; SASSERON; DUSCHL, 2016), podem tornar-se empoderados para o engajamento social, nas atividades de ensino e aprendizagem propostas e para a tomada de decisões na vida cotidiana.

A área de pesquisa em Educação em Ciências e Ensino de Biologia no Brasil já se encontra consolidada, e em sua agenda de pesquisa podemos perceber o interesse dessa comunidade científica em investigar o tema da Educação de Jovens e Adultos (EJA) como uma política educacional de importância no combate às desigualdades sociais, o que tem gerado uma quantidade de pesquisas, mesmo que ainda incipientes, mas que precisam ser analisadas, a exemplo do trabalho realizado por Sá e colaboradores (2009).

Os processos de escolarização na EJA vêm sendo analisados, e alguns trabalhos, a exemplo de Geglio e Santos (2011) e Morais (2009), tem apontado que o Ensino de Biologia na EJA quando comparado ao ensino regular tem sofrido na forma como os conteúdos são ministrados, tanto em ralação a quantidade como na qualidade, sendo tratados de maneira breve e superficial e através de metodologias pouco apropriadas, onde muitas vezes não geram interesse por parte dos alunos por serem também descontextualizados do seu dia-a-dia. Esses conteúdos científicos são geralmente muitos extensos e descontextualizados, sendo inadequados a EJA. A pesquisa de natureza bibliográfica, como esta, é importante porque apresenta uma visão panorâmica dos aspectos que vem sendo pesquisados sobre o assunto, e mostra como os esforços vêm sendo canalizados para uma EJA crítica e comprometida com a formação da cidadania e com o processo de alfabetização científica dos jovens e adultos.

Em se tratando de uma pesquisa bibliográfica foi utilizado, como algumas referências básicas, trabalhos de estado da arte. Tais investigações têm grande relevância pelo fato de apresentarem, por meio de sistemáticas e consistentes revisões bibliográficas (PEREIRA; TRIVELATO, 2017), inventário, organização, sistematização, descrição e análise do estado do conhecimento ou tendências de pesquisas de ensino (SLONGO; DELIZOICOV, 2010; PEREIRA; TRIVELATO, 2017). 
Os objetivos deste trabalho são apresentar um panorama das pesquisas em Educação em Ciências e Ensino de Biologia sobre EJA em cinco periódicos nacionais Qualis A e analisar as características desses trabalhos em relação a regiões de origem do trabalho, focos temáticos (principais temas e abordagens) e procedimentos metodológicos de investigação utilizados.

\section{METODOLOGIA}

A pesquisa apresentada é uma Pesquisa Bibliográfica, numa abordagem qualitativa com uso da Análise de Conteúdo (BARDIN, 2008). Estudos com essa abordagem têm representado importantes ferramentas auxiliares na caracterização e no mapeamento do conjunto de conhecimentos produzidos em uma dada área de investigação (SILVA; LOPES JÚNIOR, 2013), e tentam responder sobre quais aspectos e dimensões vêm sendo destacados e como e sob quais condições têm sido produzidas as pesquisas em suas diferentes modalidades e canais, ou veículos de publicação, ou divulgação (FERREIRA, 2002). Por isso, pode permitir uma visibilidade panorâmica das investigações brasileiras sobre Educação de Jovens e Adultos (EJA) na Educação em Ciências e no Ensino de Biologia, publicadas em periódicos nacionais, particularmente sobre características e aspectos que têm sido tratados nessas pesquisas.

Investigaram-se 5 periódicos nacionais da área de Educação em Ciências Qualis A (Revista Ciência \& Educação; Revista Investigações em Ensino de Ciências - IENCI; Revista Brasileira de Pesquisa em Educação em Ciências - RBPEC; Ensaio: Pesquisa em Educação em Ciências e Revista Alexandria). Inicialmente foi realizado um levantamento e mapeamento das publicações onde buscaram-se os termos 'Educação de Jovens e Adultos', 'EJA', 'Ensino de Ciências e EJA', 'Ensino de Biologia e EJA', 'Ensino de Ciências e Educação de Jovens e Adultos' e ‘Ensino de Biologia e Educação de Jovens e Adultos'. Os termos foram utilizados no processo de busca ou pesquisa nos sites dos referidos periódicos e localizados nos títulos e nas palavras-chave, quando sugestivo e necessário, a abordagem dos temas pelos artigos, foi identificada através da leitura do resumo e do artigo por inteiro. 
Em uma etapa posterior, foi realizada a análise das publicações. Para isto, foram escolhidos alguns aspectos ou descritores propostos por Pereira e Trivelato (2017) e Sá et al. (2009). Foram utilizados os seguintes descritores: distribuição geográfica (região de origem do trabalho), focos temáticos e procedimentos metodológicos de investigação: tipo de abordagem de pesquisa; instrumentos ou fontes de coleta de dados; tipo de análise de dados.

Finalmente, as produções acadêmicas foram caracterizadas e classificadas de acordo com os descritores discriminados, e os resultados são apresentados na forma de quadros (1, 2 e 3$)$ e gráfico (figura 1).

\section{RESULTADOS E DISCUSSÃO}

$\mathrm{Na}$ análise realizada em cinco periódicos nacionais especializados em publicações de pesquisas em Educação em Ciências e Ensino de Biologia, Qualis A, localizaram-se um número de 20 investigações relacionadas à modalidade de ensino EJA. Destes, foram considerados para a análise 14 artigos que estão diretamente relacionados com o ensino de ciências e de biologia. No quadro 1 são apresentados os títulos dos 14 trabalhos e os respectivos periódicos e ano de publicação.

De acordo com os resultados no quadro 1, constatou-se que ainda é pouco o número de investigações em Educação em Ciências e Ensino de Biologia sobre EJA.

Quadro 1 - Trabalhos de pesquisa em educação em ciências e ensino de Biologia sobre EJA localizados em periódicos nacionais Qualis A - CAPES

\begin{tabular}{|c|c|c|c|}
\hline $\mathbf{N}^{\mathbf{0}}$ & Título & Periódico & Ano \\
\hline 1 & $\begin{array}{c}\text { O ensino de ciências naturais e cidadania sob a ótica de } \\
\text { professores inseridos no programa de aceleração de } \\
\text { aprendizagem da EJA - educação de jovens e adultos }\end{array}$ & Ciência \& Educação & 2005 \\
\hline 2 & $\begin{array}{c}\text { Configurações curriculares mediante o enfoque CTS: } \\
\text { desafios a serem enfrentados na educação de jovens e } \\
\text { adultos }\end{array}$ & Ciência \& Educação & 2007 \\
\hline 3 & $\begin{array}{c}\text { Educação em ciências e educação de jovens e adultos: } \\
\text { pela necessidade do diálogo entre campos e práticas }\end{array}$ & Ciência \& Educação & 2008 \\
\hline
\end{tabular}




\begin{tabular}{|c|c|c|c|}
\hline 4 & $\begin{array}{l}\text { Abordagem temática e contextos de vida em uma } \\
\text { prática educativa em ciências e biologia na EJA }\end{array}$ & Ciência \& Educação & 2011 \\
\hline 5 & $\begin{array}{c}\text { Aprendizagem significativa na EJA: uma análise da } \\
\text { evolução conceitual a partir de uma intervenção didática } \\
\text { com a temática energia }\end{array}$ & $\begin{array}{l}\text { Investigações em } \\
\text { Ensino de Ciências }\end{array}$ & 2014 \\
\hline 6 & $\begin{array}{c}\text { A articulação da tríade CTS: Reflexões sobre o } \\
\text { desenvolvimento de uma proposta didática aplicada no } \\
\text { contexto da EJA }\end{array}$ & $\begin{array}{l}\text { Investigações em } \\
\text { Ensino de Ciências }\end{array}$ & 2016 \\
\hline 7 & $\begin{array}{l}\text { Estilos de pensamento de professores de química da } \\
\text { educação de jovens e adultos (EJA) do Paraná em } \\
\text { processo de formação permanente }\end{array}$ & $\begin{array}{l}\text { Ensaio: Pesquisa em } \\
\text { Educação em } \\
\text { Ciências }\end{array}$ & 2014 \\
\hline 8 & $\begin{array}{l}\text { Argumentação e a construção de oportunidades de } \\
\text { aprendizagem em aulas de ciências }\end{array}$ & $\begin{array}{l}\text { Ensaio: Pesquisa em } \\
\text { Educação em } \\
\text { Ciências }\end{array}$ & 2015 \\
\hline 9 & $\begin{array}{c}\text { A formação educacional na EJA: Dilemas e } \\
\text { Representações Sociais }\end{array}$ & $\begin{array}{l}\text { Ensaio: Pesquisa em } \\
\text { Educação em } \\
\text { Ciências }\end{array}$ & 2015 \\
\hline 10 & $\begin{array}{l}\text { Abordagem temática: desafios na educação de jovens e } \\
\text { adultos }\end{array}$ & $\begin{array}{l}\text { Revista Brasileira de } \\
\text { Pesquisa em } \\
\text { Educação em } \\
\text { Ciências (RBPEC) }\end{array}$ & 2007 \\
\hline 11 & $\begin{array}{c}\text { A Educação em Biologia na Educação de Jovens e } \\
\text { Adultos (EJA): Etnografia de uma experiência } \\
\text { biocêntrica na escola }\end{array}$ & $\begin{array}{l}\text { Revista Brasileira de } \\
\text { Pesquisa em } \\
\text { Educação em } \\
\text { Ciências (RBPEC) }\end{array}$ & 2011 \\
\hline 12 & $\begin{array}{l}\text { Plantas Medicinais no Ensino de Química e Biologia: } \\
\text { Propostas Interdisciplinares na Educação de Jovens e } \\
\text { Adultos }\end{array}$ & $\begin{array}{l}\text { Revista Brasileira de } \\
\text { Pesquisa em } \\
\text { Educação em } \\
\text { Ciências (RBPEC) }\end{array}$ & 2014 \\
\hline 13 & $\begin{array}{c}\text { O início, o fim e o meio: algumas concepções e imagens } \\
\text { de estudantes da EJA sobre menstruação, menopausa e } \\
\text { climatério }\end{array}$ & $\begin{array}{l}\text { Revista Brasileira de } \\
\text { Pesquisa em } \\
\text { Educação em } \\
\text { Ciências (RBPEC) }\end{array}$ & 2016 \\
\hline 14 & $\begin{array}{l}\text { O Ensino de Ciências e Matemática na Educação de } \\
\text { Jovens e Adultos: um estudo de caso sobre ação docente }\end{array}$ & Alexandria & 2011 \\
\hline
\end{tabular}


Fica constatado que entre os quatorze trabalhos analisados, encontraram-se 03 publicações na década de 2000-2010, e na década de 2010 até os dias atuais foi obtido o maior número de publicações, ou seja, 11 trabalhos.

Nossos resultados corroboram com os encontrados por SÁ et al., 2009 ao analisar pesquisas apresentadas nas actas/anais do Encontro Nacional de Pesquisa em Educação em Ciências (ENPEC), mesmo existindo um crescente e significativo crescimento no número de estudos voltados ao ensino de Ciências e EJA, ainda são poucos os realizados quando comparados a outras modalidades de ensino.

3.1 A EJA na pesquisa em educação em ciências (EC) e ensino de biologia (EB) de acordo com as regiões brasileiras - distribuição geográfica

Outro aspecto interessante que foi analisado é a distribuição geográfica das pesquisas sobre Ensino de Ciências e Biologia na EJA. Aqui considerou-se o total de 20 trabalhos identificados sobre EJA. Foram verificadas as regiões brasileiras com maiores contribuições com essas pesquisas, bem como as principais instituições onde essas pesquisas têm sido realizadas. A figura 1 ilustra a distribuição geográfica dos trabalhos.

Conforme os dados constantes na figura 1 as regiões brasileiras que têm concentrado o maior número de pesquisas sobre EJA, de acordo com os trabalhos publicados nos periódicos analisados, é o Sul, com oito publicações, e o Sudeste, com sete publicações. No Centro-Oeste foram identificadas três publicações, e no Nordeste duas publicações, regiões com menor número de publicações. Não foi identificado nenhum trabalho para a região Norte.

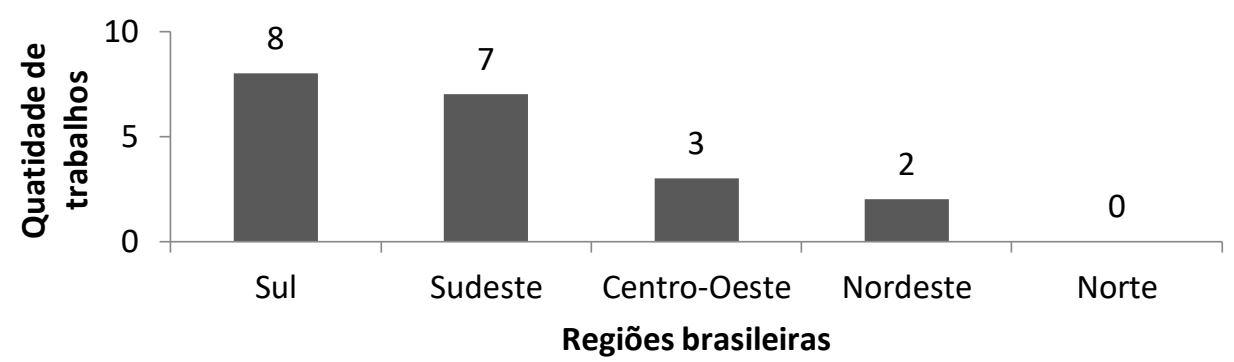

Figura 1- Pesquisas em EC e EB sobre EJA de acordo com as diferentes regiões brasileiras. 
O fato da maior parte das publicações serem oriundas das regiões Sul e Sudeste confirma os resultados de outros autores para este aspecto (SÁ et al., 2009; PEREIRA; TRIVELATO, 2017), quando afirmam que é nestas regiões que se concentram o maior número de programas de pós-graduação em Educação em Ciências no Brasil e instituições de ensino superior com tradição na realização de tais pesquisas. As instituições com maior número de publicações em EC, EB e EJA foram Universidade Federal de Santa Catarina (UFSC) e Universidade Federal de Santa Maria (UFSM) (3 trabalhos cada); Instituto Federal do Rio de Janeiro (IFRJ); Universidade Federal do Rio de Janeiro (UFRJ) (02 trabalhos cada). É também nas regiões Sul e Sudeste que se concentram mais recursos financeiros para a pesquisa, o que acaba influenciando na maior quantidade de publicações e pesquisas realizadas.

\subsection{Focos temáticos e procedimentos metodológicos nas publicações sobre a EJA}

No quadro 2 - observamos os focos temáticos (em negrito) com os respectivos trabalhos.

Quadro 2 - Distribuição das publicações entre os focos temáticos privilegiados e proporções.

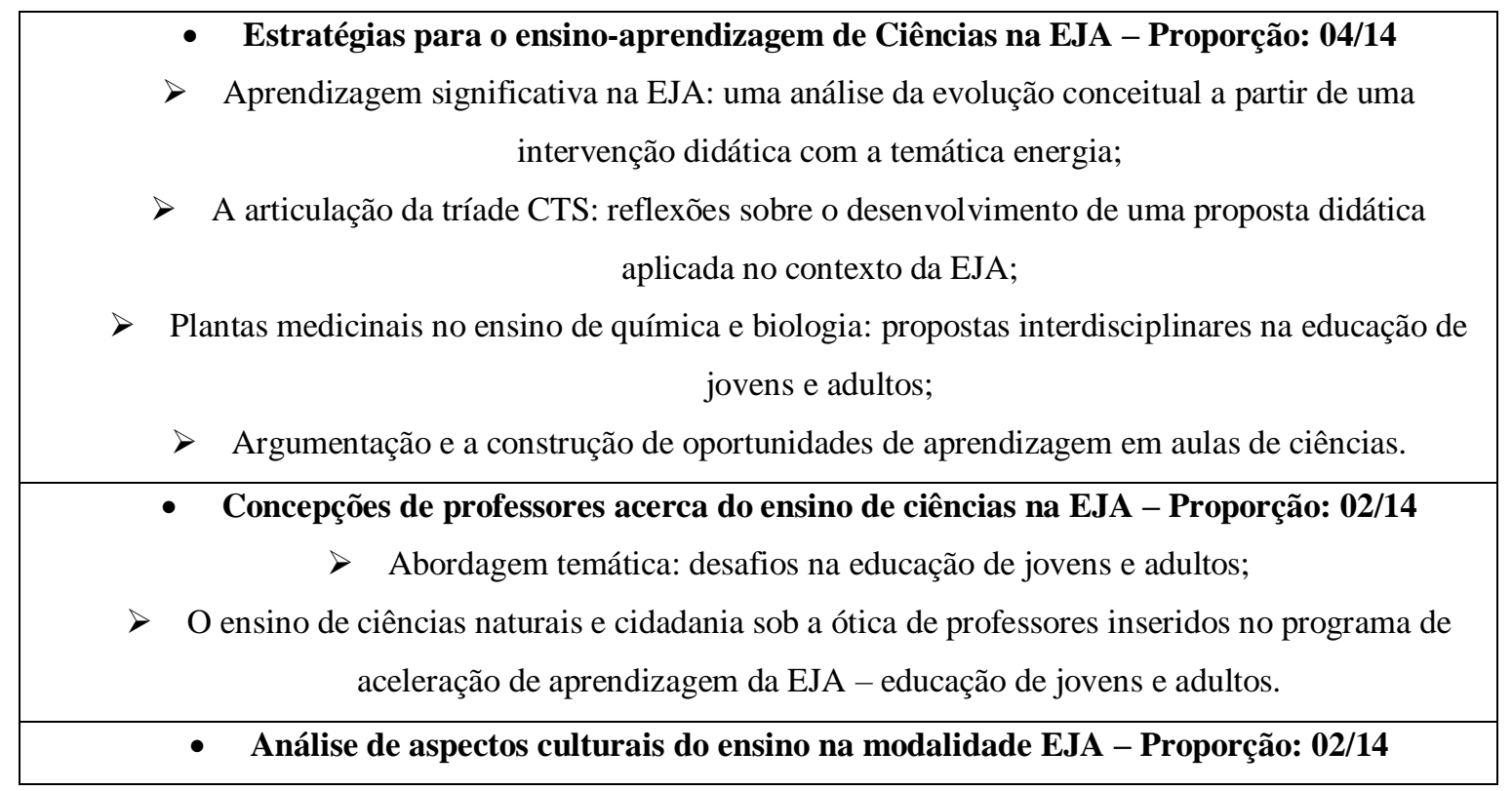




\begin{tabular}{|c|c|}
\hline$>$ & $\begin{array}{l}\text { A Educação em Biologia na Educação de Jovens e Adultos (EJA): Etnografia de uma } \\
\text { experiência biocêntrica na escola; } \\
\text { O Ensino de Ciências e Matemática na Educação de Jovens e Adultos: um estudo de caso sobre } \\
\text { ação docente. }\end{array}$ \\
\hline • & $\begin{array}{l}\text { Concepções dos alunos acerca de temas relacionados à Ciência e à EJA - Proporção: 03/14 } \\
>\text { O início, o fim e o meio: algumas concepções e imagens de estudantes da EJA sobre } \\
\text { menstruação, menopausa e climatério; } \\
\text { Abordagem temática e contextos de vida em uma prática educativa em ciências e biologia na } \\
\text { EJA; } \\
>\text { A formação educacional na EJA: dilemas e representações sociais. }\end{array}$ \\
\hline$>$ & $\begin{array}{c}\qquad \text { Currículo - Proporção: 02/14 } \\
\text { Educação em ciências e educação de jovens e adultos: pela necessidade do diálogo entre campos } \\
\text { e práticas; } \\
\text { Configurações curriculares mediante o enfoque CTS: desafios a serem enfrentados na educação } \\
\text { de jovens e adultos. }\end{array}$ \\
\hline & 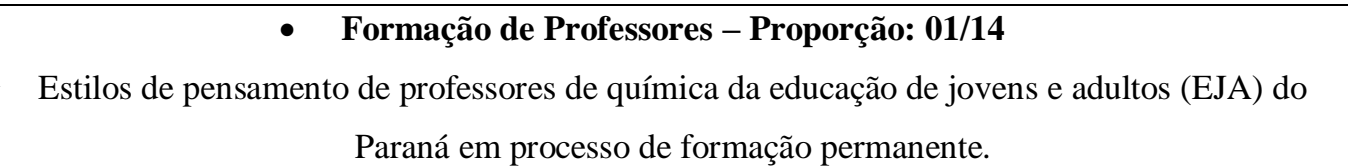 \\
\hline
\end{tabular}

Com relação aos focos temáticos das publicações, temos a seguinte distribuição: a maior quantidade de publicações teve como foco 'estratégias para o ensino-aprendizagem de Ciências na EJA' com 04 trabalhos; 'concepções dos alunos acerca de temas relacionados à Ciência e à EJA' com 03 trabalhos; 'currículo' com 02 trabalhos; 'concepções de professores acerca do ensino de ciências na EJA' e 'Análise de aspectos culturais do ensino na modalidade EJA', com 02 trabalhos cada e 'Formação de Professores', com 01 trabalho.

O número maior de trabalhos focados em estratégias para ensino-aprendizagem de Ciências na EJA' pode ser fruto de estudos que mostram a necessidade de novas estratégias para o engajamento dos alunos. Cavalcante, 2011 em trabalho realizado com população carcerária e a modalidade EJA, utilizando filmes como forma para problematizar conceitos de Biologia, percebeu dois pontos que se mostraram benéficos para o momento de aprendizagem. O primeiro ponto faz referência ao momento em si, o 
momento do filme fez com que eles se desconectassem do cotidiano da prisão, se concentrando no enredo do filme, levando ao segundo ponto, onde os alunos puderam fazer reflexões baseadas em suas vivências, podendo praticar a visão crítica. Já estudo realizado por Bortoluzzi; Coutinho, 2018 aponta que professores e alunos convergem em suas concepções sobre a necessidade e importância das aulas práticas no ensino de Biologia, porém professores optam por utilizar aulas expositivas, o que pode culminar na evasão dessa modalidade de ensino. Pesquisas que trabalham com concepções de alunos ressaltam a sua importância em entender melhor a realidade e a visão crítica dos alunos sobre o processo de ensino-aprendizagem de Ciências, sendo essa análise possível através da interpretação dos relatos dos alunos (COSTA, 2011; CAMARGO; MARTINELLI, 2006). Vale ressaltar a importância da postura do professor na relação com os alunos da EJA, na necessidade de discutir sua didática e conseguir muda-la sempre que necessário para melhor atender as necessidades de seus alunos (LOPES; SOUZA, 2005).

Com relação aos procedimentos metodológicos observa-se uma diversidade de enfoques (quadro 3) quanto a: tipo de abordagem de pesquisa; instrumentos ou fontes de coleta de dados e tipo de análise de dados.

Quadro 3 - Procedimentos metodológicos das publicações sobre EJA analisadas.

\begin{tabular}{|c|l|}
\hline TÍTULO & $\begin{array}{l}\text { Aprendizagem significativa na EJA: uma análise da evolução conceitual a partir de } \\
\text { uma intervenção didática com a temática energia. }\end{array}$ \\
\hline $\begin{array}{c}\text { PROCEDIMENTOS } \\
\text { METODOLÓGICOS }\end{array}$ & $\begin{array}{l}\text { Proposta de um módulo didático; utilização de pré e pós-questionários e ficha de } \\
\text { acompanhamento de entrega de atividades como modo de avaliação da } \\
\text { aprendizagem; Análise Textual Discursiva e processo de categorização. }\end{array}$ \\
\hline TÍTULO & $\begin{array}{l}\text { A articulação da tríade CTS: reflexões sobre o desenvolvimento de uma proposta } \\
\text { didática aplicada no contexto da EJA. }\end{array}$ \\
\hline MROCEDIMENTOS & $\begin{array}{l}\text { Sequência Didática; Pesquisa Qualitativa; Observação participante e gravação em } \\
\text { audio; elaboração de memorial descritivo-reflexivo, aplicação de questionários, } \\
\text { entrevistas e, por fim, recolha dos trabalhos produzidos pelos alunos; análise de } \\
\text { conteúdo de Bardin. }\end{array}$ \\
\hline $\begin{array}{c}\text { PROCEDIMENTOS } \\
\text { METODOLÓGICOS }\end{array}$ & $\begin{array}{l}\text { Pesquisa Qualitativa; registros escritos, sob a forma de diários, questionário e } \\
\text { entrevistas semi-estruturadas; construção de categorias }\end{array}$ \\
\hline TÍTULO & $\begin{array}{l}\text { A Educação em Biologia na Educação de Jovens e Adultos (EJA): Etnografia de } \\
\text { uma experiência biocêntrica na escola }\end{array}$ \\
\hline $\begin{array}{l}\text { PROCEDIMENTOS } \\
\text { METODOLÓGICOS }\end{array}$ & Etnografia \\
\hline TÍTULO & $\begin{array}{l}\text { Plantas Medicinais no Ensino de Química e Biologia: Propostas Interdisciplinares } \\
\text { na Educação de Jovens e Adultos }\end{array}$ \\
\hline METODOLÓGICOS & Oficina; questionário aberto. \\
\hline
\end{tabular}




\begin{tabular}{|c|c|}
\hline TÍTULO & $\begin{array}{l}\text { O início, o fim e o meio: algumas concepções e imagens de estudantes da EJA sobre } \\
\text { menstruação, menopausa e climatério }\end{array}$ \\
\hline $\begin{array}{l}\text { PROCEDIMENTOS } \\
\text { METODOLÓGICOS }\end{array}$ & $\begin{array}{l}\text { Pesquisa Qualitativa; Pesquisa-intervenção; questionário; proposta de atividades. } \\
\text { As atividades foram pensadas como práticas dialógicas, de modo a propiciarem } \\
\text { diálogos, debates, discussões que, por sua vez, foram registradas em cadernos de } \\
\text { campo e, em alguns dos encontros, com gravador. O material discursivo resultante } \\
\text { da pesquisa foi analisado segundo pressupostos metodológicos da Análise de } \\
\text { Conteúdo. }\end{array}$ \\
\hline TÍTULO & $\begin{array}{l}\text { O Ensino de Ciências e Matemática na Educação de Jovens e Adultos: um estudo } \\
\text { de caso sobre ação docente }\end{array}$ \\
\hline $\begin{array}{l}\text { PROCEDIMENTOS } \\
\text { METODOLÓGICOS }\end{array}$ & $\begin{array}{l}\text { Estudo de caso; questionários ( } 1 \text { aos discentes e } 2 \text { professores de matemática e } \\
\text { ciências); anotações em diário de campo das observações das aulas por meio do } \\
\text { estágio supervisionado }\end{array}$ \\
\hline TÍTULO & $\begin{array}{l}\text { O ensino de ciências naturais e cidadania sob a ótica de professores inseridos no } \\
\text { programa de aceleração de aprendizagem da EJA - educação de jovens e adultos }\end{array}$ \\
\hline $\begin{array}{l}\text { PROCEDIMENTOS } \\
\text { METODOLÓGICOS }\end{array}$ & Entrevista semiestruturada e a análise de documentos, com enfoque qualitativo \\
\hline TÍTULO & $\begin{array}{l}\text { Abordagem temática e contextos de vida em uma prática educativa em ciências } \\
\text { e biologia na EJA }\end{array}$ \\
\hline $\begin{array}{l}\text { PROCEDIMENTOS } \\
\text { METODOLÓGICOS }\end{array}$ & Coleta de depoimentos em forma de vídeo \\
\hline TíTUlO & $\begin{array}{l}\text { Configurações curriculares mediante o enfoque CTS: desafios a serem enfrentados } \\
\text { na educação de jovens e adultos }\end{array}$ \\
\hline $\begin{array}{l}\text { PROCEDIMENTOS } \\
\text { METODOLÓGICOS }\end{array}$ & Registros escritos, sob a forma de diários; questionário e entrevista. \\
\hline TÍTULO & $\begin{array}{l}\text { Educação em ciências e educação de jovens e adultos: pela necessidade do diálogo } \\
\text { entre campos e práticas }\end{array}$ \\
\hline $\begin{array}{l}\text { PROCEDIMENTOS } \\
\text { METODOLÓGICOS }\end{array}$ & $\begin{array}{l}\text { Análise de material que subsidia a elaboração de propostas curriculares de Ciências } \\
\text { para a EJA em âmbito nacional }\end{array}$ \\
\hline TÍTULO & $\begin{array}{l}\text { Argumentação e a construção de oportunidades de aprendizagem em aulas de } \\
\text { ciências }\end{array}$ \\
\hline $\begin{array}{l}\text { PROCEDIMENTOS } \\
\text { METODOLÓGICOS }\end{array}$ & Vídeos das aulas de ciências e notas de campo. \\
\hline TÍTULO & A formação educacional na EJA: dilemas e Representações Sociais \\
\hline $\begin{array}{l}\text { PROCEDIMENTOS } \\
\text { METODOLÓGICOS }\end{array}$ & $\begin{array}{l}\text { Questionário com questões semiestruturadas; Análise de conteúdo com o auxílio } \\
\text { do software Atlas.Ti }\end{array}$ \\
\hline TÍTULO & $\begin{array}{l}\text { Estilos de pensamento de professores de química da educação de jovens e adultos } \\
\text { (EJA) do Paraná em processo de formação permanente }\end{array}$ \\
\hline $\begin{array}{l}\text { PROCEDIMENTOS } \\
\text { METODOLÓGICOS }\end{array}$ & $\begin{array}{l}\text { Discussão, Organização e Desenvolvimento de aulas de Química e Reflexão sobre } \\
\text { a Prática Docente }\end{array}$ \\
\hline
\end{tabular}

Nas publicações analisadas, a abordagem de pesquisa mais utilizada é a qualitativa, com uso de abordagens etnográficas, dialógicas e interpretativas com o uso de questionários, entrevistas semiestruturadas, videogravações, diários, entre outros instrumentos de coleta de dados. $\mathrm{Na}$ análise de dados constatou-se desde a análise de discurso ao uso da análise de conteúdo, passando por análise de pré e pós-testes e através de categorias. Um trabalho faz uso do software Atlas-Ti, para pesquisa qualitativa. 


\section{CONSIDERAÇÕES FINAIS}

A pesquisa sobre EJA ainda é incipiente no contexto das investigações em Educação em Ciências e no Ensino de Biologia no Brasil no período estudado (20002018). Foram analisadas 14 publicações entre 20 identificadas nos cinco periódicos pesquisados. A análise realizada constata que entre os periódicos investigados, Ciência \& Educação e Ensaio: Pesquisas em Educação em Ciências e a Revista Brasileira de Pesquisa em Educação em Ciências têm publicado o maior número de artigos sobre EJA, com quatro trabalhos cada; vem a seguir Investigações em Ensino de Ciências com dois artigos e Alexandria com um artigo. Como principais tendências em focos temáticos de pesquisa têm-se: 'estratégias para o ensino-aprendizagem de Ciências na EJA', 'concepções dos alunos acerca de temas relacionados à Ciência e à EJA' e 'currículo'. Aparecem ainda 'concepções de professores acerca do ensino de ciências na EJA'; 'análise de aspectos culturais do ensino na modalidade EJA' e 'formação de professores'. As pesquisas são qualitativas, etnográficas, dialógicas e interpretativas.

Embora, seja constatada a relevância que a EJA tem para uma parte significativa da população, sobretudo, para homens e mulheres negras que residem em periferias, pessoas que moram no campo e trabalhadores que integram os grupos mais pobres da população, e que esta modalidade de educação, seja a principal "porta de entrada de conhecimento cientifico" para essas pessoas, o número de pesquisas sobre EJA em educação em ciências e ensino de biologia ainda é muito pouco. É necessário que esse tema seja mais considerado nas agendas de pesquisa na área no contexto brasileiro. O aumento de pesquisas com foco no tema pode promover a construção de práticas pedagógicas voltadas para os objetivos educacionais do ensino de Ciências e Biologia e da alfabetização científica na EJA, e a compreensão dos fenômenos do ensino e aprendizagem dos sujeitos envolvidos, mobilizando estratégias metodológicas que deverão atender a um público com experiencias de vida bem particulares e diversas, com a participação necessária de pesquisadores, professores, estudantes, gestores escolares e poder público, frente as demandas de uma educação científica crítica, humanitária e transformadora na EJA. 


\section{REFERÊNCIAS}

BARDIN, L. Análise de Conteúdo. 19 ed. Lisboa - Portugal: Edições 70, 2008.

BORTOLUZZI, L. Z.; COUTINHO, R. X. ATIVIDADES PRÁTICAS NO ENSINO DE BIOLOGIA PARA O PROEJA. EJA em Debate, v. 7, n. 11, 2018.

CAMARGO, P. S. A. S.; MARTINELLI, S. C. Educação de adultos: percepções sobre o processo ensino-aprendizagem. Psicologia Escolar e Educacional, v. 10, n. 2, p. 197 $210,2006$.

CASSAB, M. Educação de Jovens e Adultos, Educação em Ciências e Currículo: diálogos potentes. Educação em foco, v. 21, n. 1, p. 13-38, 2016.

CAVALCANTE, E. C. B. Cinema na cela de aula: o uso de filmes no Ensino de Biologia para a EJA prisional. 2011. 154 f. Dissertação (Mestrado em Ensino de Ciências) - Faculdade UnB Planaltina, Universidade de Brasília. Brasília, 2011.

COSTA, A. L. P. Alfabetização científica: a sua importância na educação de jovens e adultos. Educação \& Tecnologia, v. 13, n. 2, 2011.

FERREIRA, N. S. A. As pesquisas denominadas “Estado da Arte". Educação \& Sociedade, n. 79, p. 257-272, 2002.

GEGLIO, P. C.; SANTOS, R. C. As diferenças entre o ensino de biologia na educação regular e na EJA. Interfaces da Educação, v. 2, n. 5, p. 76-92, 2011.

GOUVEIA, D. S. M.; SILVA, A. M. T. B. A formação educacional na EJA: dilemas e representações sociais. Ensaio: Pesquisa em Educação em Ciências, v. 17, n. 3, p. 749-767, 2015.

HADDAD, S. A ação de governos locais na educação de jovens e adultos. Revista Brasileira de Educação, v. 12, n. 35, p. 197-211, 2007.

LOPES, S. P.; SOUSA, L. S. EJA: uma educação possível ou mera utopia. Revista Alfabetização Solidária (Alfasol), v. 5, 2005.

MORAIS, F. A. O ensino de Ciências e Biologia nas turmas de EJA: experiências no município de Sorriso-MT. Revista Iberoamericana de Educación, v. 48, n. 6, p. 1-6, 2009. 
OLIVEIRA, M. K. Jovens e adultos como sujeitos de conhecimento e aprendizagem. Revista Brasileira de Educação, n 12, p. 59-73, 1999.

PEREIRA, M. G.; TRIVELATO, S. L. F. A Natureza da Ciência (NDC) em publicações no ensino de Ciências e Biologia no Brasil: Uma análise preliminar. Enseñanza de las Ciencias, n. Extraordinario p. 3797-3802, 2017.

RIBEIRO, Marlene. Educação para a cidadania: questão colocada pelos movimentos sociais. Educação e pesquisa, v. 28, n. 2, p. 113-128, 2002.

SÁ, L. P. et al. Análise das pesquisas sobre EJA nos Encontros Nacionais de Pesquisa em Educação em Ciências. Atas do VIII Encontro Nacional de Pesquisa em Educação em Ciências. São Paulo - SP, 2009.

SANTOS, M. N.; SOUZA, M. L. O ensino de Ciências em turmas de educação de jovens e adultos. Atas do VIII ENPEC-Encontro Nacional de Pesquisa em Educação para Ciência, 2011.

SASSERON, L. H. Alfabetização Científica no ensino Fundamental: Estrutura e Indicadores deste processo em sala de aula. 2008. $281 \mathrm{f}$. Tese (Doutorado em Ciências) - Faculdade de Educação, Universidade de São Paulo, São Paulo, 2008. SASSERON, L. H.; DUSCHL, R. A. Ensino de ciências e as práticas epistêmicas: o papel do professor e o engajamento dos estudantes, Investigações em Ensino de Ciências, v. 21, n. 2, p. 52-67, 2016.

SILVA, C. S. F.; LOPES JÚNIOR, J. Análise documental da produção acadêmica brasileira sobre o ensino de evolução (1990-2010): caracterização e proposições. Investigações em Ensino de Ciências, v. 18, n. 2, pp. 505-521, 2013.

SLONGO, I. I. P.; DELIZOICOV, D. Teses e Dissertações em Ensino de Biologia: uma análise histórico-epistemológica. Investigação em Ensino de Ciências. v. 15, n. 2, p. 275-296, 2010. 